\title{
Eesti ja soome keele lauseehituse võrdlemisest 1980. ja 1990. aastail
}

\author{
MATI ERELT \\ Tartu Ülikool
}

Ülevaade. 1980. aastate algul käivitunud soome ja eesti keele kontrastiivse uurimise projekti "Soome ja eesti keele grammatiline võrdlus" üks põhiülesandeid oli kahe keele süntaktilise struktuuri võrdlus. Eesti poolelt vaadatuna andis projekti raames toimunud teadussuhtlus rohkesti infot ja ideid eesti keele süntaksi uurijatele ja eesti keele teadusliku grammatika koostajatele. Soome ja eesti süntaktilise struktuuri võrdluse seisukohalt oli siiski tegemist pigem ettevalmistava etapiga. Konkreetsete tulemusteni jõuti 1990. aastail, kui rahvusvahelises lingvistikas muutus üheks juhtivaks trendiks keeletüpoloogia. Turu ülikoolis algatatud jätkuprojekti "Läänemere piirkonna keelte grammatiline võrdlus" (SCLOMB) käigus loodi samanimeline korpus, mis kaasas soome ja eesti keele võrdlusesse ka nende kontaktkeeled. 1990. aastail ilmus hulk võrdlevaid artikleid, kusjuures eriti häid tulemusi saadi aspekti ja aja süsteemide võrdluses. Seni põhiliselt veaanalüüsi tulemusi käsitlev kogumik "Lähivertailuja" hakkas sisaldama ka struktuurivõrdlusi ning muutus teaduslikult kaalukamaks.

Võtmesõnad: eesti keele uurimise ajalugu; soome ja eesti keele süntaktiline võrdlus; keeletüpoloogia; veaanalüüs

Eesti ja Soome keeleteadlaste läbikäimine, mille oli katkestanud sõda ja sellele järgnenud terroriaastad, hakkas tasapisi taastuma 1960. aastate keskel pärast president Kekkose visiiti Eestisse ja laevaühenduse 
taastamist Tallinna ja Helsingi vahel. FU kongressid (eriti Helsingi 1965 ja Tallinn 1970), läänemeresoome filoloogia sümpoosionid (alates 1971) ja soome lingvistide reisid Eestisse võimaldasid saada infot Soomes tehtu kohta ning sõlmida otsesidemeid Soome ja Eesti uurijate vahel. Eesti lingvistikale oli sellest kindlasti kasu. Kuid ehk pakkus see midagi ka soome grammatikutele, eriti kui arvestada, et 1960. aastate paradigmavahetus eesti grammatikas (süntaksis Huno Rätsepa, Henno Rajandi, Ellen Uuspõllu jt tööde näol) oli toimunud täiesti sõltumatult soome lingvistikast.

1980. aastate algul käivitunud soome ja eesti keele kontrastiivse uurimise programm oli esimene samm infovahetuselt otsese koostöö suunas. Soome keeleteadlase vaatevinklist on sellest andnud põhjaliku ülevaate Matti Punttila (1997) ja Hannu Remes (2004). Püüan siinses kirjutises lühidalt kirjeldada tollast tegevust eestlase seisukohast, piirdudes seejuures süntaksiga, täpsemalt selle uurimusliku poolega, süvenemata veaanalüüsi (sm virheanalyysi) probleemidesse.

Teatavasti pärineb mõte teha soome ja eesti keele lauseehituse kontrastiivsel uurimisel koostööd Tampere ülikooli soome ja üldkeeleteaduse õppetooli õppejõududelt Valma Yli-Vakkurilt ja Heikki Paunoselt. Seda arutati mitteametlikult 1980. aastal Turu kongressi ajal. 1982. aastal toimus Tvärminnes Helsingi ülikooli uurimisjaamas seminar, millest võtsid osa nii soome lingvistid kui ka Soomes töötavad eesti keele lektorid ning kus arutati kavandatava projekti sisu ja tegevusvorme. Kui esialgu oli mõttes olnud ainult süntaksi uurimine, siis seminaril arvati õigemaks tegelda kogu grammatikaga. Seejuures eristati kahte suunda: puhtteadusliku ehk uurimusliku suunana keelestruktuuride võrdlust ja rakendusliku suunana veaanalüüsi. Tegevusvormidena plaaniti ühisseminare, rühmatööd jm (vt lähemalt Yli-Vakkuri \& Remes 1983; Remes 2004). Projekti algatajad ja eestvedajad Valma Yli-Vakkuri ja Heikki Paunonen käisid seejärel Eestis nõu pidamas Tallinna ja Tartu keeleteadlastega. Et enamik Soome ülikoolide eesti keele lektoreid olid Tartu ülikooli õppejõud ja seega kavandatava projektiga nagunii seotud, siis arvati Tartus, et ülikooli osalus projektis on juba piisavalt suur. Seevastu 
Keele ja Kirjanduse Instituudi (KKI) grammatikasektoris oldi koostööst uurimuslikus suunas, s.o keelestruktuuride võrdluse alal vägagi huvitatud. Sektoris koostati parajasti eesti keele teaduslikku grammatikat (EKG) ning selle autoritel oli kasulik arutada soome kolleegidega sarnaseid probleeme.

1983. aasta septembris Helsingis toimunud Soome ja NSV Liidu teaduslik-tehnilise koostöökomisjoni keeleteaduse töörühma istungil lülitati soome ja eesti keele kontrastiivuurimine nimetuse all "Soome ja eesti keele grammatiline võrdlus” koostööprogrammi ning kinnitati 1984. ja 1985. aasta üritused. Nii struktuuri võrdlus kui ka veaanalüüs toimus selle programmi raames kuni Eesti iseseisvuse taastamiseni 1991. aastal. Struktuuri võrdluse põhilised koostöövormid olid ühisseminarid ja teemapartnerite arutelud. Kahepäevane, tervelt 23 ettekandega koordineerimisseminar peeti Tallinnas 1983. aasta septembris (vt Erelt 1984). Edasi toimusid seminarid enam-vähem kordamööda Tallinnas - 1985 (vt Erelt 1986), 1987 (vt Erelt 1988), 1988 ning Soomes: Helsingis - 1984 (vt Erelt 1985), 1987 ja Turus - 1989. Et soomlastel oli võimalik käia Eestis ka väljaspool koostööprogrammi, siis toimusid koostööpartnerite kokkusaamised mõnevõrra sagedamini kui seminarid. 1989. aasta Turu seminaril otsustati, et suuri ühisseminare enam ei korraldata ning edasine töö toimub iga teemarühma liikmete vahelise arutelu kujul. Ühisseminaridel peetud ettekannetest kogumikke ei koostatud. Küll avaldas osa eesti grammatikuid oma laiendatud ettekande (enamasti teoksil oleva grammatika osa) preprindina, et selles käsitletuga oleks võimalik põhjalikumalt tutvuda ja arutelu saaks tulemuslikum. Kogumikud koostati veaanalüüsi seminaride ettekannetest. Need ilmusid korraldava ülikooli toimetiste sarjas ning kandsid alates 1985. aastast nime "Lähivertailuja". Esimene veaanalüüsi seminar toimus Summasaares 1983. aasta mais, seejärel igal aastal mõne ülikooli uurimisbaasis. Seminarist võtsid osa põhiliselt Soome ülikoolide eesti keele lektorid (seminarid olid ühtlasi eesti lektorite kokkutulekud) ja mõned soome õppejõud. Alates 1991. aastast, kui seminaris hakati pidama ka keelestruktuuride võrdlust käsitlevaid ettekandeid, nimetati need seminarid ümber kontrastiivseminarideks. 
Struktuuri võrdluse allprojektis osalenud soome lingvistide seltskond oli küllaltki suur ja väga esinduslik. Siin olid Soome ülikoolide tuntuimad lingvistid ja parimad eesti keele tundjad, nt Auli Hakulinen, Pentti Leino, Seppo Suhonen ja Hannu Tommola Helsingi ülikoolist, Mauno Koski, Kalevi Wiik, Eeva Kangasmaa-Minn ja Päivi Rintala Turu kahest ülikoolist, Heikki Paunonen ja Valma Yli-Vakkuri Tampere ülikoolist, Helena Sulkala ja Irmeli Pääkkönen Oulu ülikoolist, Hannu Remes ja Ilkka Savijärvi Joensuu ülikoolist.

Eesti pool oli sellega võrreldes tagasihoidlikum. Siia kuulusid (kes pikemat, kes lühemat aega) KKI grammatikasektori teadurid Helle Metslang, Kaja Tael, Silvi Vare, Kristiina Kross (Ross), Toomas Help, Joel Sang ja Mati Erelt, sektorist Tallinna pedagoogilisse instituuti siirdunud Mati Hint ja Krista Kerge, mujalt Tallinnast veel Ants Pihlak. Tartlastest lõid kaasa Ellen Uuspõld ja Reet Kasik, osa aega lektorina Soomes.

Süntaksiteemadest olid kohtumistel arutluse all käänete funktsioonid, eriti aspektiga seonduv subjekti, objekti ja predikatiivi käändevaheldus, aeg ja aspekt, tegumoed, kommunikatiivsed lausetüübid ja kõneviisid, eitus, pragmasüntaks ehk grammatiliste kategooriate sekundaarkasutus, infiniitkonstruktsioonid, relatiivpronoomenid, sõnajärg ja üht-teist muudki. Projekti toimimisajal veel ühegi teema käsitlemisel ühisuurimuseni välja ei jõutud. See oli üsna ootuspärane, sest eranditult kõigi jaoks oli kontrastiivuurimine lisatöö muude ülesannete kõrval. Tulemuslikuks ühistööks oli ka projektis pakutud kooskäimise võimalusi liiga napilt. Eestis siiski üksikuid võrdlevaid süntaksiuurimusi ilmus, täpsemalt on tegu uurimustega, kus soome keel on taustaks. Näiteks Ants Pihlakult, kes tegi koostööd Hannu Tommolaga, ilmus artikkel “Tegumood eesti keeles (võrrelduna soome keelega)” (Pihlak 1990), Kaja Taelalt preprint "Sõnajärjemallid eesti keeles (võrrelduna soome keelega)" (Tael 1988). Peale võrdlevate uurimuste ilmus ka mitmeid soome süntaksikäsitlustest inspireeritud kirjutisi. Näiteks Valma Yli-Vakkuri tollal vägagi uudse soome pragmasüntaksi ehk grammatiliste vormide sekundaarse (afektiivse) kasutuse käsitluse (Yli-Vakkuri 1986) mõju on näha nii Helle Metslangi artiklis "Eesti hüüdlausest afektiivse süntaksi taustal" 
(1990) kui ka Mati Erelti artiklis "Kõneleja ja kuulaja kaudse väljendamise võimalusi eesti keeles" (1990).

Nagu juba öeldud, oli KKI grammatikute jaoks kõige olulisem see, mis kasu tõuseb koostööst soome lingvistidega EKG-le. Et grammatika süntaksiosa sai valmis enam-vähem samal ajal kui kontrastiivprojekt lõppes, siis projekti raames tehtu sai grammatikat mõjutada terve projekti jooksul. Mõistagi on raskevõitu öelda, mida täpselt kirjutada just selle koostöö arvele. Kuivõrd kontrastiivseminaride süntaksiarutelude üheks põhiteemaks oli aspekt ja sellega seotud kategooriad, mida soome lingvistid Eeva Kangasmaa-Minn, Pentti Leino, Hannu Tommola jt olid tõhusalt uurinud, siis kindlasti oli aspektiga seotu, nagu aluse, sihitise, öeldistäite, sihitisekäändelise määruse käändekasutus, ajavormide kasutus jm, olulisemaid mõjuvaldkondi. Muidugi kuulub siia ka juba nimetatud pragmasüntaks. Lausete liigitus põhitüüpidekski, mis on süntaksi olulisemaid klassifikatsioone, pärineb ideena samuti soome süntaksist, ehkki tüübistik ise on meie grammatikas mõnevõrra teistsugune. Ning ühtteist võis olla veelgi. Kasu nii grammatikale kui ka kogu meie teadustegevusele ei toonud mitte üksnes konkreetsete süntaksiteemade läbiarutamine, vaid ka üldisem teaduslik arutelu, keeleteadusliku kirjanduse vahetus, võimalus töötada Soome raamatukogudes jne, st teadussuhtlus laiemas tähenduses.

Süntaktiliste struktuuride tegeliku võrdluseni jõuti alles pärast soome-eesti kontrastiivse uurimise projekti lõppu. Niisiis võib seda projekti vähemalt süntaksi osas pidada pigem soome-eesti kontrastiivset uurimist ettevalmistavaks projektiks kui kontrastiivuurimise enda projektiks. EKG-ga seotud uurijate, aga ka mitme teise eesti lingvisti huvi hakkas pärast EKG valmimist 1990. aastate esimesel poolel järjest rohkem kalduma seniselt üsna eestikeskselt uurimiselt tüpoloogilise uurimise poole. Rahvusvahelises lingvistikas oli keeletüpoloogia muutunud üheks juhtivaks trendiks. Euroopas oli käsil suurejooneline rahvusvaheline tüpoloogiaprojekt EUROTYP, kuhu kaasati paljude keelte asjatundjaid, sealhulgas Soomest ja Eestist. Tundub, et vähemalt osaliselt ja vähemalt Eestis oli just tüpoloogiline suund see, millega seoses suurenes 
ka huvi eesti ja soome keele kõrvutava uurimise vastu. Nende probleemidega tegelemist soodustas suuresti koostöötingimuste normaliseerumine pärast Eesti iseseisvumist. Helsingisse sõit sai peagi sama lihtsaks ja tavaliseks kui sõit Tallinnast Tartusse.

Tüpoloogiatrendiga haakus hästi Valma Yli-Vakkuri 1991.aastal Turu ülikoolis algatatud ja lõppenud kontrastiivprojekti (täpsemalt selle süntaksi osaprojekti) jätkuprojekt. See kandis nime "Läänemere piirkonna keelte grammatiline võrdlus" ehk SCLOMB ning kaasas soome ja eesti keele süntaktilisse võrdlusesse ka nende kontaktkeeled. Projekti raames koostati samanimeline tekstikorpus, mis koosnes Läänemere piirkonna keelte (soome, eesti, saksa, rootsi, vene, läti ja leedu) ilukirjandustekstidest - iga keele originaaltekstist ja selle tõlkeist ülejäänud keeltesse. Sellisena pidi korpus võimaldama välja selgitada nii struktuuritüpoloogilisi kui ka pragmaatilisi ühisjooni ja erinevusi (vt Yli-Vakkuri 1992; 1993). Korpust on kasutatud mitmetes uurimustes, olen seda teinud ka ise. Projekti väljaandena ilmus Valma Yli-Vakkuri toimetatud kogumik "Studia comparativa linguarum orbis Maris Baltici 1. Tutkimuksia syntaksin ja pragmasyntaksin alalta” (1993), mis sisaldas viis kirjutist. Eeva Kangasmaa-Minn (1993) käsitleb seal aspekti ja sellele lähedasi nähtusi soome-ugri keeltes, Helle Metslang (1993) eesti keele ajakategooriat, Hannu Tommola (1993) tegumoodi ja muid diateetilisi nähtusi soome ja eesti keeles, Tuomas Huumo (1993) võrdleb soome ja eesti sõnajärge ning Mati Erelt ja Matti Punttila (1993) vaatlevad reduplikatsiooni eesti ja soome keeles. Hannu Tommola oli teinud koostööd Ants Pihlakuga, kuid mõlemad pidasid siiski õigemaks avaldada oma seisukohad enamvähem samadest asjadest eraldi artiklitena (Pihlak 1990; Tommola 1993). Seevastu Matti Punttila ja minu artikkel (Erelt \& Punttila 1993) oli vist esimene soome-eesti ühisartikkel kõrvutava uurimise vallas. Kahjuks jäi kogumik nr 1 ainsaks selle sarja väljaandeks.

1990. aastate esimese poole tüpoloogilises eesti-soome kõrvutavas uurimises tõuseb esile Helle Metslangi Oulu ülikoolis kaitstud artikliväitekiri "Temporal Relations in the Predicate and the Grammatical System of Estonian and Finnish” (Metslang 1994a). Väitekirja põhieesmärk 
on eesti ja soome keele ajasüsteemide kirjeldus ja võrdlus, kõrvaleesmärk eesti ja soome keele kogu grammatilise süsteemi võrdlus. Iseäranis huvitav on just selle tüpoloogilise tausta avamine, mis seletaks aja väljendamise erinevusi eesti ja soome keeles. See on esitatud kahes artiklis: "Grammatikaliseerumisest eesti ja soome keeles" (Metslang 1994b) ja "Kielet ja kontrastit" (varem 1994c). Metslang näitab, et peale selle, et eesti keel on soome keelega võrreldes vähem aglutineeriv ja rohkem analüütiline, on see ka vähem grammatiseerunud, selles on vähem grammatikat kui soome keeles. Metslang lisab veel kolm erinevust eesti ja soome keele grammatilise süsteemi vahel: 1) soome keel taotleb süsteemiikoonilisust ehk isomorfismi, s.o vastavust "üks sisuüksus - üks vormiüksus", eesti keel tekstiikoonilisust, s.o teksti struktuuri vastavust denotaadi struktuurile; 2) eesti keeles on vastavus tsentri ja perifeeria, markeerimata ja markeeritud vahel suurem kui soome keeles; 3 ) soome keeles on rohkem sekundaargrammatikat, s.o põhigrammatikale tuginevat afektiivset grammatikat.

Nagu juba eespool nimetatud, muutus 1980. aastate soome-eesti kontrastiivseminaride lõppedes kaalukamaks veaanalüüsi seminaride ja neid kajastava kogumiku "Lähivertailuja" sisu. Ehkki mõningaid süntaktilise struktuuri võrdlust käsitlevaid kirjutisi oli neis varemgi, nt Ellen Uuspõllu kirjutis eitava lause sõnajärjest (1983) või Tõnu Seilenthali aspekti käsitlev artikkel (1988), tuli põhjalikumaid struktuurivõrdlusi, sealhulgas keeletüpoloogiat arvestavaid, põhiliselt siiski alates aastast 1992. Sisu avardumist arvestades oli ka seminari nimetus aasta varem muudetud veaanalüüsi seminarist kontrastiivseminariks. Eesti poolt esindasid neil seminaridel ja "Lähivertailujas" endiselt eelkõige Soomes töötavad õppejõud, kuid neis osales ka teisi eesti uurijaid. Ettekannetega esinesid ja kirjutisi avaldasid mitmed soome lingvistid. Helle Metslang käsitles grammatiseerumist eesti ja soome keeles (1994b), prefiksaaladverbi ära ja seda sisaldavate lausete vasteid soome keeles (1996), ajakategooriat soome ja eesti keeles (1994d) ning soome konditsionaalivormide vasteid eesti keeles (1999). Birute Klaas vaatles daativis, eesti keeles adessiivis või allatiivis lauseelemendi (Emal valutab pea, Ema pesi 
lapsel jalgu, Isa andis pojale viiuli) staatust ja väljendusvõimalusi Balti keeleareaalis (1992; 1994), Ellen Uuspõld võrdles soome ja eesti sise- ja väliskohakäänete kasutust kohamääruse väljendajatena (1992), Hannu Remes relatiivlausete pronoomenikasutust (1992), Tuomas Huumo soome ja eesti keele sõnajärjeerinevusi (1994), Renate Pajusalu muutumisverbide (1994) ning Ilona Tragel ja Margit Mikkilä modaalverbide saama ja võima (1994) kasutust. Mati Erelt ja Matti Punttila kirjeldasid soome ja eesti keele reduplikatsiooni (1992; 1999), aproksimatiivsuse väljendusvõimalusi (1994) ning intensiivsussõnu (1996). Uuel sajandil muutus taas järk-järgult "Lähivertailuja" suunitlus ja sisu, kuni sellest sai esinduslik rakenduslingvistika ajakiri.

Soome ja eesti keele lauseehitust uuriti juba 1990. aastatel kõrvutavalt mujalgi kui siin kirjeldatud projektide raames. Nimetatagu näiteks Tartu ülikooli tüpoloogiliste uurimuste sarja "Estonian: Typological Studies I-V” (1996-2001), kus samuti leidub mitu olulist artiklit eesti-soome võrdluste vallast. Aga see ei kahanda sugugi Soome-Eesti kontrastiivuuringute tähtsust, millel on peale teadusliku panuse ka meie koostööja sõprussuhete sümboli tähendus.

\section{Kirjandus}

Erelt, Mati 1984. Soome-eesti kontrastiivuuringud algamas. - Keel ja Kirjandus $12,711$.

Erelt, Mati 1985. Soome-eesti kontrastiivseminar Soomes. - Keel ja Kirjandus 2, 123-124.

Erelt, Mati 1986. Soome-eesti kontrastiivseminar Tallinnas. - Keel ja Kirjandus 1,62 .

Erelt, Mati 1988. Soome-eesti ühisseminar. - Keel ja Kirjandus 2, 127-128.

Erelt, Mati 1990. Kõneleja ja kuulaja kaudse väljendamise võimalusi eesti keeles. Keel ja Kirjandus 10, 35-39.

Erelt, Mati, Matti Punttila 1992. Reduplikatiivsed võrdlustarindid absoluutse superlatiivi väljendusvahendeina eesti ja soome keeles. - Lähivertailuja 6, $7-23$.

Erelt, Mati, Matti Punttila 1993. Lausesisesest tõhustusreduplikatsioonist eesti ja soome keeles. - SCLOMB 1, 159-172. 
Erelt, Mati, Matti Punttila 1994. Approksimatiivisuuden ilmaisemisesta virossa ja suomessa. - Lähivertailuja 8, 1-8.

Erelt, Mati, Matti Punttila 1996. Suomen ja viron intensiteettisanoista. - Lähivertailuja 9, 23-30.

Erelt, Mati, Matti Punttila 1999. Suomalais-ugrilaisten kielten reduplikaatiosta. Lähivertailuja 10, 3-12.

Huumo, Tuomas 1993. Suomen ja viron kontrastiivista sanajärjestysvertailua. SCLOMB 1, 97-158.

Huumo, Tuomas 1994. Näkökulmia suomen ja viron sanajärjestyseroihin. - Lähivertailuja $8,21-39$.

Kangasmaa-Minn, Eeva 1993. Aspektista ja sen sukulaisilmiöistä suomalais-ugrilaisissa kielissä. - SCLOMB 1, 13-23.

Klaas, Birute 1992. Vaba daativi väljendusvõimalustest Balti keeleareaalis. - Lähivertailuja $6,37-44$.

Klaas, Birute 1994. Adressaatobjekt Balti keeleareaalis. - Lähivertailuja 7, 52-64.

Lähivertailuja 3. Suomalais-virolainen virheanalyysiseminaari Hailuodossa 15.16.5.1987. Peep Nemvalts, Päivi Rintala (Toim.). Turun yliopiston suomalaisen ja yleisen kielitieteen julkaisuja 34. Turku, 1988.

Lähivertailuja 5. Suomalais-virolainen kontrastiivinen seminaari Virroilla 27. ja 28. syyskuuta 1991. Maia Väkram (Toim.). Folia Fennistica \& Linguistica 15. Tampere: Tampereen yliopiston suomen ja yleisen kielitieteen laitos, 1992.

Lähivertailuja 6. Suomalais-virolainen kontrastiivinen seminaari Mekrijärvellä 10.-11.4.1992. Hannu Remes (Toim.). Kielitieteellisiä tutkimuksia 27. Joensuu: Joensuun yliopisto, Humanistinen tiedekunta, 1992.

Lähivertailuja 7. Suomalais-virolainen kontrastiivinen seminaari Tammivalkamassa 5.-7.5.1993. Karl Pajusalu, Valma Yli-Vakkuri (Toim.). Turun yliopiston suomalaisen ja yleisen kielitieteen laitoksen julkaisuja 44. Turku, 1994.

Lähivertailuja 8. Suomalais-virolainen kontrastiivinen seminaari Hailuodossa 7.-9.5.1994. Helena Sulkala, Heli Laanekask (Toim.). Oulun yliopiston suomen ja saamen kielen laitoksen tutkimusraportteja 40. Oulu, 1994.

Lähivertailuja 9. Suomalais-virolainen kontrastiiviseminaari 3.-5.5.1996, Lammi. Riho Grünthal, Reet Kasik (Toim.). Castrenianumin toimitteita 53. Helsinki: Helsingin yliopiston suomalais-ugrilainen laitos, Suomalais-ugrilainen seura, 1997.

Lähivertailuja 10. Suomalais-virolainen kontrastiivinen seminaari Tampereella 14. toukokuuta 1998. Lembit Vaba, Heikki Hurtta (Toim.). Folia Fennistica \& 
Linguistica 23. Tampere: Tampereen yliopiston suomen kielen ja yleisen kielitieteen laitos, 1999.

Metslang, Helle 1990. Eesti hüüdlausest afektiivse süntaksi taustal. - Keel ja Kirjandus 10, 598-606.

Metslang, Helle 1993. Viron aika: muoto, merkitys, ikonisuus. - SCLOMB 1, 24-40.

Metslang, Helle 1994a. Temporal Relations in the Predicate and the Grammatical System of Estonian and Finnish. Oulun yliopiston suomen ja saamen kielen laitoksen tutkimusraportteja 39. Oulu.

Metslang, Helle 1994b. Grammatikaliseerumisest eesti ja soome keeles. - Lähivertailuja 7, 9-32.

Metslang, Helle 1994c. Kielet ja kontrastit. - Virittäjä 2, 203-226.

Metslang, Helle 1994d. Mõnda ajast eesti ja soome keeles. - Lähivertailuja 8, 62-73.

Metslang, Helle 1996. Eesti prefiksaaladverbist ära soome keele taustal. - Lähivertailuja 9, 31-46.

Metslang, Helle 1999. Soome konditsionaalivormide tõlkimisest eesti keelde. Lähivertailuja 10, 47-60.

Pajusalu, Renate 1994. Muutumisverbid eesti keeles ja nende vasted soome keeles. - Lähivertailuja 8, 83-97.

Pihlak, Ants 1990. Tegumood eesti keeles (võrrelduna soome keelega). - Voprosy sopostavitel’nogo issledovanija jazykov (grammatičeskij aspekt). Tallinskij pedagogičeskij institut im. E. Vilde. Tallinn., 59-84.

Punttila, Matti 1997. Soome ja eesti keele kontrastiivne uurimine. - Lähivertailuja 9, 7-13.

Remes, Hannu 1992. Pronominien käytöstä viron relatiivilauseissa. - Lähivertailuja 6, 45-52.

Remes, Hannu 2004. Kaks aastakümmet kontrastiivseminare. - Keel ja Kirjandus 4, 295-300.

Seilenthal, Tõnu 1988. Aspektist ja muust eesti ja soome keeles. Esialgseid märkmeid. - Lähivertailuja 3, 52-59.

Tael, Kaja 1988. Sõnajärjemallid eesti keeles (võrrelduna soome keelega). Preprint KKI-56. (Läänemeresoome keeleteaduse sümpoosion. Turku, 30.8.2.9.1988.) Eesti NSV Teaduste Akadeemia Keele ja Kirjanduse Instituut. Tallinn.

Tommola, Hannu 1993. Ambipersoonainen suppressiivi: Diateesista suomessa ja virossa. - SCLOMB 1, 41-96.

Tragel, Ilona, Margit Mikkilä 1994. Suomen ja viron saada- ja voida-verbien vertailuja kognitiivisesta näkökulmasta. - Lähivertailuja 8, 114-123. 
SCLOMB 1 = Studia comparativa linguarum orbis Maris Baltici 1. Tutkimuksia syntaksin ja pragmasyntaksin alalta. Valma Yli-Vakkuri (Toim.). Turun yliopiston suomalaisen ja yleisen kielitieteen laitoksen julkaisuja 43. Turku, 1993.

Uuspõld, Ellen 1983. Sanajärjestyksestä viron ja suomen kielteisessä lauseessa. Suomalais-virolainen virheanalyysiseminaari Summasaaressa 18. ja 19. toukokuuta 1983. Valma Yli-Vakkuri, Hannu Remes (Toim.). Folia Fennistica \& Linguistica 10. Tampereen yliopiston suomen kielen ja yleisen kielitieteen laitoksen julkaisuja 10. Tampere, 20-24.

Uuspõld, Ellen 1992. Sise- ja väliskohakäänded lokaaladverbiaali väljendajatena. Lähivertailuja 6, 79-84.

Yli-Vakkuri, Valma 1986. Suomen kieliopillisten muotojen toissijainen käyttö. Turun yliopiston suomalaisen ja yleisen kielitieteen laitoksen julkaisuja 28. Turku.

Yli-Vakkuri, Valma 1992. Tutkimushanke Itämeren piirin kielten syntaktinen vertailu. - Lähivertailuja 5, 53-54.

Yli-Vakkuri Valma 1993. Tutkimushanke Itämeren piirin kielten kieliopillinen vertailu - Studia comparativa linguarum orbis Maris Baltici. - SCLOMB $1,9-12$.

Yli-Vakkuri, Valma, Hannu Remes 1983. Lukijalle. - Suomalais-virolainen virheanalyysiseminaari Summasaaressa 18. ja 19. toukokuuta 1983. Valma Yli-Vakkuri, Hannu Remes (Toim.). Folia Fennistica \& Linguistica 10. Tampereen yliopiston suomen kielen ja yleisen kielitieteen laitoksen julkaisuja 10. Tampere, 3. 


\title{
On the comparison of Estonian and Finnish sentence structure in the 1980s and 1990s
}

\author{
MATI ERELT \\ University of Tartu
}

One of the primary goals of the project "Grammatical comparison of Finnish and Estonian", initiated in the 1980s, was to compare the syntactic structure of the two languages. From the Estonian perspective, the scientific dialogue that took place due to the project provided considerable information and new ideas to those who were researching Estonian syntax and compiling a scientific grammar of Estonian. As regards the comparison of the syntactic structure of Finnish and Estonian, however, this was merely a preliminary phase. Concrete results were achieved in the 1990s, when typology became a leading trend in international linguistics. In the follow-up project "Grammatical comparison of the languages of the Baltic region" (SCLOMB), initiated at the University of Turku, a corpus bearing the same name was created, also including the contact languages of Finnish and Estonian. The 1990s saw the publication of numerous contrastive studies; particularly impressive results were achieved in the comparison of tense and aspect systems. The compendium "Lähivertailuja", which had previous focused primarily on the results of error analysis, began to include comparisons of language structure and became more scientifically significant.

Keywords: history of Estonian study; syntactic comparison of Finnish and Estonian; language typology; error analysis

\section{Mati Erelt}

Tartu Ülikooli eesti keele ja üldkeeleteaduse instituut

Jakobi 2

51014 Tartu, Estonia

mati.erelt@ut.ee 